\title{
COGNIÇÃO SITUADA: fundamentos e relações com a Ciência da Informação
}

SITUATED COGNITION: principles and relations with Information Sscience

Ludmila Salomão Venâncio - salomao@eci.ufmg.br Mestranda em Ciência da Informação da Escola de Ciência da Informação da UFMG

Mônica Erichsen Nassif Borges - mnassif@eci.ufmg.br Doutora em Ciência da Informação, docente da Escola de Ciência da Informação da UFMG e coordenadora do Grupo de Estudos Cognitivos em Ciência da Informação - GECCI

Comente este artigo no blog Ebibli = http://encontros-bibli-blog.blogspot.com/

\section{Resumo}

Discute os fundamentos da abordagem cognitiva denominada Cognição Situada e estabelece relações com a Ciência da Informação. Apresenta os conceitos de informação e conhecimento definidos pelas abordagens atuais sobre a cognição humana e, ao final, evidencia perspectivas para o relacionamento entre os dois campos de conhecimento.

Palavras-chave: Ciências Cognitivas. Cognição Situada. Informação. Conhecimento.

\section{INTRODUÇÃO}

As Ciências Cognitivas influenciam diversas áreas do conhecimento, tais como: neurociência, lingüística, psicologia cognitiva, sociologia, antropologia, filosofia e outras; cada qual contribui, de acordo com suas perspectivas, com subsídios que ajudam a compreender, conceber e pensar o conhecimento e o saber humano. (DUPUY 1996)

Inúmeras abordagens têm sido propostas para explicar o fenômeno da cognição, as quais podem ser agrupadas em duas vertentes, conforme o estatuto ontológico da realidade que assumem. A primeira é objetiva assumindo a realidade como pré-dada e independente do sujeito; e a segunda é não-objetiva assumindo a realidade como construída pelo sujeito no seu curso de interação com o ambiente.

As abordagens dominantes das Ciências Cognitivas são baseadas no objetivismo. As principais conhecidas como cognitivismo e conexionismo, partilham alguns princípios, sendo o principal deles o princípio cartesiano-analítico-objetivista. Esse princípio caracteriza-se por estabelecer a separação sujeito/objeto, ou "mundo das coisas" e "mundo da mente", e por considerar o mundo como algo objetivo cujas características e relações podem ser captadas e representadas na mente do indivíduo, restando aos observadores a tarefa de recuperá-las adequadamente, seja por meio de símbolos ou estados sub-simbólicos globais. 
No Cognitivismo, a mente equivale a um computador, a uma máquina, e, como tal, possui um repertório de instrumentos (um mapa de representações do mundo e a linguagem) que lhe permite resolver problemas. A cognição é entendida como a solução de problemas e, aprender significa criar representações do mundo, independente e externo, através da assimilação de novas experiências. A literatura cognitivista trata de como o observador processa informação a partir da imagem da retina, com as categorias de representações já existentes na mente, e como essas categorias são armazenadas na memória. (MAGRO, 1999, von KROGH e ROOS, 1995)

Outra vertente das Ciências Cognitivas é o conexionismo que, como o cognitivismo, também trabalha com a idéia de que a mente é processadora de informações. Ainda prevalece a idéia de representação, não mais inata, mas adquirida com a experiência através das interações com o meio. A inspiração do conexionismo baseia-se na biologia, ao contrário do cognitivismo, cujas bases estão na física. Para os conexionistas, os organismos não são simplesmente análogos às máquinas, mas são máquinas. Warren McCulloch e Walter Pitt, fundadores dessa corrente, acreditam que o cérebro é uma variedade ainda mal compreendida de máquinas computacionais. Em outros termos, cada neurônio é uma calculadora aritmética elementar que computa uma função booleana. O cérebro é, portanto, representado como uma rede de interconexões entre tais calculadoras, os neurônios.

Em contraposição, situam-se algumas abordagens cognitivas, entre elas o arcabouçoteórico conceitual que, na literatura, vem sendo denominado de Cognição Situada. Sob essa perspectiva, a dicotomia sujeito-objeto não é válida, pois a realidade é vista como algo que depende do seu observador. É o próprio ser humano que constrói o seu mundo, na dinâmica do viver, incessante e interativo.

$\mathrm{O}$ artigo tem por objetivo discutir os fundamentos da Cognição Situada e estabelecer as relações existentes com a Ciência da Informação. Os princípios-chave da Cognição Situada são contrapostos às vertentes predominantes das ciências cognitivas. Discutem-se os aspectos relacionados aos conceitos de informação e conhecimento, que podem abrir novas possibilidades de estudos para a Ciência da Informação e por fim, são apresentadas perspectivas para o relacionamento entre os dois campos de conhecimento.

\section{OS PRINCÍPIOS DA COGNIÇÃO SITUADA: POSSIBILIDADES INOVADORAS PARA A DISCUSSÃO SOBRE INFORMAÇÃO E CONHECIMENTO}


A Cognição Situada abrange diversas abordagens, dentre as quais: Biologia do Conhecer, proposta por Maturana \& Varela (2001); Cognição Situada, designada por Clancey (1997), Enactive View, desenvolvida por Varela, Thompson \& Rosch (1991); e Ecologia da Mente, analisada por Bateson (1972). Essas abordagens têm como princípio epistemológico fundamental a existência do organismo-em-seu-ambiente, ou seja, organismo e ambiente constituem uma unidade inseparável, e a dinâmica de interação ocorre contínua e simultaneamente.

Ao contrário das abordagens predominantes nas ciências cognitivas, que consideram os indivíduos como sistemas abertos (processadores de informações, que recebem entradas, processam e geram saídas), Maturana \& Varela (2001) vêm os seres vivos como um sistema fechado informacionalmente e determinado estruturalmente. Por sistemas determinados estruturalmente entendem-se os sistemas em que nada que lhes seja externo possa especificar as mudanças estruturais pelas quais eles passam em conseqüência de uma interação. Assim, um agente externo que interage com um sistema estruturalmente determinado, pode somente desencadear mudanças estruturais determinadas pelo próprio sistema.

Como resultado desse determinismo estrutural, um sistema vivo opera sempre em interação estrutural no meio e existe, como tal, enquanto essa interação for congruente. $\mathrm{Ou}$ seja, um organismo vive em constante interação no meio, de maneira co-determinada, o viver de um modula e é modulado pelo viver do outro, constituindo um todo inseparável, imbricado. Enquanto existir essa congruência, meio e organismo atuarão como possíveis perturbações mútuas que desencadearão, ou não, mutuamente mudanças estruturais. Como afirma Maturana (1997, p.62):

A história de vida de todo organismo é uma história de mudanças estruturais coerente com a história de mudanças estruturais do meio em que ele existe, realizada através da contínua e mútua seleção das respectivas mudanças estruturais.

A Cognição Situada define que todo ato cognitivo é um ato experiencial, e, portanto, situado, resultante do acoplamento estrutural e da interação congruente do organismo-em-seuambiente. A cognição não é, portanto, a representação de um mundo pré-concebido, cujas características podem ser especificadas antes de qualquer atividade cognitiva. Ao contrário, é ação incorporada "... é a atuação de um mundo com base em uma história da diversidade de ações desempenhadas por um ser no mundo”. (VARELA, THOMPSON \& ROSCH, 1991, p. 9)

Nessa perspectiva, não somos meros expectadores passivos de um mundo pré-dado e independente de nós. O mundo em que vivemos depende de nossa estrutura biológica, que 
especifica o meio em que vivemos, de forma contingente com a dinâmica das mudanças estruturais indivíduo-e-meio.

\subsection{Informação e conhecimento}

Os conceitos relativos à informação e conhecimento são apresentados nesta seção tal como são discutidos nas abordagens cognitivas, não havendo a intenção de argumentações positivas ou negativas sobre eles.

No âmbito da Ciência da Informação, a informação e o conhecimento têm sido discutidos principalmente sob o olhar das abordagens cognitivistas e conexionistas. Essa perspectiva evidencia que o processo de interação entre o indivíduo e uma determinada estrutura de informação gera uma modificação no estado cognitivo do sujeito, produzindo conhecimento que se relaciona corretamente com a informação recebida.

A visão da informação como elemento gerador de conhecimento do indivíduo pode ser exemplificado pelo mentalismo de BROOKES (1980), uma das expressões mais significativas da abordagem cognitivista na Ciência da Informação. Para BROOKES (1980, p.131), o conhecimento “... [é] uma estrutura de conceitos ligados por suas relações e informação [é] como uma pequena parte dessa estrutura”. A estrutura de conhecimento, que pode ser tanto subjetiva quanto objetiva, é transformada pela informação em uma nova estrutura de conhecimento. Tal mudança pode ser expressa pela equação $\mathrm{K}[\mathrm{S}]+\Delta \mathrm{I}=\mathrm{K}[\mathrm{S}+\Delta \mathrm{S}]$, na qual a estrutura de conhecimento $\mathrm{K}[\mathrm{S}]$ é modificada para uma nova estrutura $\mathrm{K}[\mathrm{S}+\Delta \mathrm{S}]$ pela informação $\Delta \mathrm{I}$, e $\Delta \mathrm{S}$ indicando a mudança.

Já na Cognição Situada, a informação é vista como uma possível perturbação da estrutura biológica do ser que pode ou não ser determinada em função da sua própria estrutura e da sua história de interações com o meio. Como argumentado por Magro (1999, p.202):

... os seres vivos não mantêm interações instrutivas com o meio e não há informação no ambiente capaz de instruí-los inequivocamente: em cada caso, a informação e o que é "relevante" dependem do instante estrutural do organismo do indivíduo, que lhe permite tomar algum evento como tal, uma vez que os organismos são sensíveis a cada instante às perturbações do meio, de uma maneira que é determinada por sua estrutura".

Dessa forma nós, seres humanos, não "captamos informações" do meio, ao contrário, construímos um mundo, ao especificarmos quais as configurações do meio são perturbações, e que mudanças estas desencadeiam em nosso organismo. 
As abordagens dominantes das Ciências Cognitivas sugerem que a informação esteja contida no ambiente, restando ao sujeito captá-la e representá-la simbolicamente na mente. Nesta perspectiva, a memória é um lugar onde essas representações estão armazenadas, bem como todas as regras criadas pelo sujeito para manipular esses símbolos. Assim, relembrar algo significa receber um símbolo, como entrada, processá-lo (fazendo um matching com os padrões simbólicos armazenados) e recuperar o símbolo do lugar onde ele está armazenado, gerando uma saída.

De forma distinta, a memória na Cognição Situada é vista como um processo dinâmico, uma habilidade para reconstruir ou re-desempenhar o mesmo comportamento. Nos dizeres de Clancey (1997, p. 68): “... memória é a habilidade para agir similarmente à maneira que nós agimos anteriormente, para re-atuar, sequenciar e compor interações passadas". Lembrar, então, não pode ser visto como um caminho neural ou traço que é simplesmente reativado, mas como um processo consciente de re-vivenciar uma experiência prévia, que envolve uma atitude emocional sobre essa experiência.

Para a Cognição Situada, o conhecimento não se limita ao processamento de informações oriundas de um mundo anterior à experiência do observador, não é passivo, mas sim construído pelo ser vivo em suas interações com o mundo. Conhecer não é um processo de acumulação de representações do ambiente, mas está relacionado às mudanças estruturais que ocorrem no organismo de maneira contingente com sua história de interações com o meio. O conhecimento humano não é um artefato de armazenamento na memória nem tão pouco uma cópia da realidade, ao contrário é ação efetiva: “... ação que permite um ser vivo continuar sua existência no mundo que ele mesmo traz à tona ao conhecê-lo". (MATURANA,1997, p.23)

Desta forma, conhecer é apresentar uma conduta adequada, uma conduta congruente com a circunstância na qual essa mesma conduta se realiza, sendo determinada pela estrutura do indivíduo.

Maturana \& Varela (2001) destacam que toda a reflexão, inclusive, a que se faz sobre os fundamentos do conhecer humano, ocorre necessariamente na linguagem. Estamos na linguagem, movendo-nos nela, sendo ela a maneira particular de sermos humanos. Para esses autores, a linguagem não é um sistema de signos e regras utilizado para a comunicação. Ela ocorre somente no fluir de coordenações de conduta consensuais recursivas, ou coordenações de coordenações de ação, entre organismos. Assim, tudo o que nós fazemos, fazemos na linguagem guiados pelas nossas emoções, como argumentado por Maturana \& Varela (2001, p.257): 
... percebemo-nos num mútuo acoplamento lingüístico, não porque a linguagem nos permita dizer o que somos, mas porque somos na linguagem, num contínuo ser nos mundos lingüísticos e semânticos que geramos com os outros.

Nesse sentido, as emoções são disposições corporais dinâmicas que especificam, a cada momento, os domínios de ação nos quais nos movemos. Não há, portanto, ação humana sem uma emoção que a estabeleça como tal, e a torne possível como ação. Como afirmado por Maturana (1998, p.92) “... nada nos ocorre, nada fazemos que não esteja definido como uma ação de um certo tipo por uma emoção que a torna possível”.

$\mathrm{O}$ viver humano se dá, então, em um contínuo entrelaçamento entre linguagem e emoções. Nossas ações na linguagem mudam ao mudarem nossas emoções, e nossas emoções mudam ao mudarem nossas ações na linguagem. Isto significa que, só conhecemos quando há pré-disposição emocional e interações congruentes na linguagem.

\section{RELAÇÕES ENTRE A COGNIÇÃO SITUADA E A CIÊNCIA DA INFORMAÇÃO}

O relacionamento entre a Ciência da Informação e a Cognição Situada envolve a compreensão dos múltiplos processos cognitivos relacionados ao comportamento de usuários de sistemas, produtos e serviços de informação.

As questões que a Cognição Situada discute mostram possibilidades de estudos mais avançados sobre o comportamento de usuários da informação em domínios diversos. Com base nos conceitos sobre informação, conhecimento, emoção e linguagem, revisitados pelas abordagens cognitivas atuais, é possível observar os usuários com maior clareza e com mais amplitude, considerando aspectos relativos ao contexto e a comportamentos específicos. Esses diferentes contextos podem incluir organizações de qualquer natureza, grupos sociais e atividades a que usuários estejam ligados, tais como leitura, pesquisa e, aspectos relacionados ao tratamento e gerenciamento da informação.

Além disso, é possível considerar os princípios dessa abordagem cognitiva no que se refere à organização e tratamento da informação para o aprimoramento de sistemas de informação. Essa possibilidade ocorre especificamente quando se considera o uso desses sistemas pelos seus usuários, assim como a formulação dos requisitos para recuperação da informação.

Embora sejam importantes as contribuições oferecidas pela Cognição Situada, ainda são poucos os estudos desenvolvidos no âmbito da Ciência da Informação que utilizam essa base teórica - o que se observa é a predominância das discussões embasadas nos princípios 
das vertentes cognitivista e conexionista. Os estudos que adotam a perspectiva das abordagens cognitivas atuais têm sido desenvolvidos principalmente em ambientes organizacionais enfatizando a gestão da informação, a gestão do conhecimento e a inteligência competitiva.

Sendo assim, a ciência da informação não pode se furtar a incorporar os princípios das abordagens cognitivas do campo da Cognição Situada, uma vez que eles trazem discussões que alteram as concepções arraigadas na área sobre a informação e o conhecimento. É possível que, ao se compreender as bases teóricas sobre a cognição humana na visão contemporânea, muitas das indagações que ainda inquietam a Ciência da Informação possam ser resolvidas, ou pelo menos observadas sob um ponto de vista mais amplo e atual.

\section{REFERÊNCIAS}

BATESON, Gregory. Steps to an ecology of mind. New York: Ballantine Books, 1972.

Mind and nature: A necessary unit. New York: Bantam Books, 1988.

BORGES, Mônica Erichesen Nassif. A informação e o conhecimento na biologia do conhecer uma abordagem cognitiva para os estudos sobre inteligência empresarial. 2002 (Doutorado em Ciência da Informação) - PPGCI, Escola de Ciência da Informação da UFMG, Belo Horizonte.

A aplicabilidade da biologia do conhecer no âmbito da Ciência da Informação. Revista DataGramaZero, v.4, n.3, jun. 2003.

BORGES, Mônica Erichsen Nassif et al. Estudos cognitivos em Ciência da Informação. Revista Encontros Bibli, $\mathrm{n}^{\mathrm{o}}$ 15, 2003. Disponível em: www.encontros-bibli.ufsc.br/ Edicao_15/borges_estudoscognitivos.pdf. Acesso em: 30 jun. 2006.

A Ciência da Informação discutida à luz das teorias cognitivas: estudos atuais e perspectivas para a área. Cadernos BAD, n. 2, 2004.

BROOKES, B.C. The foundations of information science: Part I: Philosophical Aspects. Journal of Information Science, v. 2, p. 125-133, 1980

CLANCEY, W. J. Situated cognition: on human knowledge and computer representations. Cambridge University Press, 1997. 406p.

DUPUY, J. P. Nas origens das ciências cognitivas. Trad. FERREIRA, R.L. São Paulo: Editora da Universidade Estadual Paulista, 1996. 228 p.

von KROGH, George, ROOS, Johan Organizational epistemology. New York: Martin's Press, 1995.

LIMA, Gercina Ângela Borem de Oliveira. A navegação em sistemas de hipertexto e seus aspectos cognitivos. Cadernos BAD, n. 1, 2004. 
LIMA, Gercina Ângela Borem de Oliveira; RAGHAVAN, K.S. Information retrieval and cognitive research. Knowledge Organization, v.31, n.2, 2004.

MAGRO, Maria Cristina. Linguajando o linguajar: da biologia à linguagem. 1999 (Doutorado em Lingüística) - Instituto de Estudos da Linguagem,UNICAMP, Campinas.

MATURANA, H.R. A ontologia da realidade. Organizadores: GRACIANO, V.; MAGRO, C.; VAZ, N. Belo Horizonte: Editora UFMG, 1997.

Emoções e linguagem na educação e na política. Trad. : FORTES, J. F. C. Belo Horizonte: Editora UFMG, 1998.

Cognição, ciência e vida cotidiana. Organizadores: MAGRO, C.; PAREDES, V. Belo Horizonte: Editora UFMG, 2001.

MATURANA, H. R.; VARELA, F.J. A Árvore do Conhecimento: as bases biológicas da compreensão humana. Trad. MARIOTTI, H.; DISKIN, L. São Paulo: Palas Athenas, 2001.

VARELA, F.; THOMPSON, E.; ROSCH, E. The Embodied Mind: Cognitive Science and Human Experience. Cambridge: MIT Press, 1991.

\begin{abstract}
It discusses the principles of the approach named Situated Cognition and its relations with the information science. It presents the concepts of information and knowledge defined by modern approaches about the human cognition and, at the end, it highlights perspectives for the relationship between the two fields of knowledge.
\end{abstract}

KEYWORDS: Cognitive Sciences. Situated Cognition. Information -Knowledge.

Originais recebidos em 05/04/2006. 